Article

\title{
Non-Energy Use of Fuels in the Greenhouse Gas Emission Reporting
}

\author{
Eva Krtková ${ }^{1, *}$, Vladimir Danielik ${ }^{2}$, Janka Szemesová ${ }^{3}$, Klára Tarczay ${ }^{4}$, Gábor Kis-Kovács ${ }^{4}$ and \\ Vladimir Neuzil ${ }^{5}$ \\ 1 Czech Hydrometeorological Institute, Na Sabatce 17, 14306 Prague 412, Czech Republic \\ 2 Faculty of Chemical and Food Technology, Department of Inorganic Technology, Slovak Technical University, \\ Radlinského 9, 81237 Bratislava, Slovakia \\ 3 Department of Emissions and Biofuels, Slovak Hydrometeorological Institute, Jeséniova 17, \\ 83315 Bratislava, Slovakia \\ 4 Hungarian Meteorological Service, Unit of National Emissions Inventories, Kitaibel Pál utca 1, \\ 1024 Budapest, Hungary \\ 5 KONEKO marketing, Ltd., Sojovicka 2, 19700 Prague 9, Czech Republic \\ * Correspondence: eva.krtkova@chmi.cz; Tel.: +420-244-03-2422
}

Received: 19 June 2019; Accepted: 12 July 2019; Published: 17 July 2019

check for updates

\begin{abstract}
In the context of greenhouse gas emissions, $\mathrm{CO}_{2}$ emissions from fuels are not arising only from combustion of the fuels, but also from non-energy use of fuels. In order to keep the inventory transparent, comparable, accurate, consistent, and complete, it is necessary to carefully assess such emissions in order to neither not omit nor double count them. The paper presents the methodological guidance of non-energy use of fuels given by Intergovernmental Panel on Climate Change (IPCC) 2006 Guidelines. Further, approaches of the Czech Republic, Slovak Republic, and Hungary, three neighboring countries, for reporting $\mathrm{CO}_{2}$ emissions from non-energy use of fuels are presented and discussed.
\end{abstract}

Keywords: greenhouse gas inventory; fuels; energy; industrial processes; reporting

\section{Introduction}

Concerns about the fate of the Earth climate system culminated in 1992 at the United Nations Conference on Environment and Development in Rio de Janeiro (Brazil), where the United Nations Framework Convention on Climate Change (UNFCCC) was adopted. The Convention entered into force in 1994. The basic objective of the convention was to create the preconditions for the early stabilization of global atmospheric greenhouse gas concentrations at a level that would prevent dangerous interference with anthropogenic influences with the climate system [1,2].

However, the convention did not specify specific reduction targets, so negotiations on strengthening the convention were launched in 1995 and the so-called Kyoto Protocol (KP) was adopted in 1997, specifying the reduction targets of the economically developed countries [1,3].

By adopting the KP, the economically advanced countries were required to reduce greenhouse gas emissions individually or collectively by at least 5.2\% during the first period of 2008-2012, compared to 1990 levels. Concerned emissions and sinks of carbon dioxide $\left(\mathrm{CO}_{2}\right)$, methane $\left(\mathrm{CH}_{4}\right)$, nitrous oxide $\left(\mathrm{N}_{2} \mathrm{O}\right)$, partially (HFC) and fully (PFC) fluorinated hydrocarbons, and sulfur hexafluoride (SF6), expressed as aggregated $\mathrm{CO}_{2}$ emissions. In the case of the Czech Republic and Slovakia this was a commitment to reduce total greenhouse gas emissions by $8 \%$ compared to the 1990 reference year (1995 is the reference for HFC, PFC, and SF6) $[1,2,4]$. Hungary has a very specific base year under the $\mathrm{KP}$, it is the average of $1985-1987$ years. 
In December 2012, an amendment was agreed at the 18th Conference of the Parties (COP 18) in Doha (Qatar) confirming the continuation of the Kyoto Protocol and its second period of Commitment 2 (2013-2020) [1]. Under Annex 1, paragraph C, of Decision 1/CMP.8, States of Appendix 1 to the Convention are obliged to accept new reduction commitments that should contribute to reducing greenhouse gas emissions by at least $18 \%$ below 1990 levels [5]. 20\%, the European Union will fulfill its commitment to the convention or the KP within the community [1].

The $20 \%$ reduction corresponds to the objective set out in the relevant EU regulations adopted under the 2009 climate and energy package, and the EU has even offered a 30\% increase (i.e. decrease in emissions) in the commitment if the other major world economies would have made a stricter commitment. The climate-energy package includes, among other things, a directive amending and extending the European Emission Trading Scheme (EU ETS) [1].

In December 2015, COP 21 was held in Paris. It was expected to reach a worldwide unified agreement (the Paris Agreement), which applies jointly to all parties, with the aim of keeping global warming below $2{ }^{\circ} \mathrm{C}$. To this end, each UN country had to submit a plan to reduce emissions by $2030[1]$.

To control the compliance with the commitments, a mechanism for annual greenhouse gas emission inventories has been created. All parties to the convention report their inventory of greenhouse gas emissions and sinks annually as of 15 April. In order for the EU, as one of the parties to the convention, to also be able to send its inventory on 15 April, it needs an inventory from its Member States at an earlier date [1]. Thus, by Regulation (EU) No 525/2013 (and before already by Decision No 280/2004/EC), the Member States are prescribed two additional deadlines, 15 January and 15 March [6,7]. As of January 15 , the inventory has a preliminary form, some of the necessary data for emission calculations is not available before this date [1].

\subsection{Methodology for the Greenhouse Gas Emission Inventories}

The methodology used for greenhouse gas emission inventories was created by the Task Force on Greenhouse Gas Inventory (TFI) within the Intergovernmental Panel on Climate Change. The originally used methodology was published in 1996, respectively [1,8]. However, this methodology did not include methodologies for all sources of greenhouse gas emissions and sinks, and in 2000 the Good Practice Guidance was published [9]. This methodological manual included the addition and extension of methodological procedures for estimating greenhouse gas emissions for some specific subcategories. Subsequently, updated IPCC 2006 Guidelines were developed [10]. This latest and currently valid methodology contains detailed procedures for estimating emissions and sinks of greenhouse gases for all sectors, as well as for estimating key categories, uncertainties, and other mandatory inventory components [1].

Emissions and sinks of greenhouse gas emissions (GHG) are determined by origin from specific sectors-Energy, Industrial Processes, and Product Use, Agriculture, Land Use, and Land Use Change, and Forestry and Waste. Each sector has more detailed categories of greenhouse gas emissions. It is good practice to report emissions or sinks at the lowest possible category level [1,8-10].

The methodological manual from 2006 has been used for the inventory of emissions and sinks of greenhouse gases since 2015, for the inventory, which shows emissions for the time series 1990-2013, i.e., it already interferes with the second commitment period of the Kyoto Protocol.

\subsection{Combustion of Fuels}

In many countries, the energy sector plays a major role in the greenhouse gas emissions. It usually covers about $70 \%$ to $90 \%$ of greenhouse gas emissions in $\mathrm{CO}_{2}$ equivalent of the total emissions. The attention is therefore drawn to this sector in order to manage accurate, consistent, comparable, complete, and transparent reporting of greenhouse gas emissions, which arise from this sector. There are a number of specifics that have to be treated carefully while compiling the inventory. One of them 
is overlap of some of the processes with 'Industrial processes and other product use' sector (IPPU), especially in the case of fuels used in different industrial production $[10,11]$.

Emissions of $\mathrm{CO}_{2}$ from fuels in the inventories of greenhouse gases are arising not only from the combustion, but also from its non-energy use. The inventory compilers have to carefully make sure that these emissions are not accounted twice in the inventory. As IPCC 2006 Guidelines state, when activity data for fuel used represents the deliveries to enterprises or main subcategories, there is a high risk of double counting of such emission. Therefore combustion statistics are the preferred option for the activity data in this case [10].

The share of $\mathrm{CO}_{2}$ from non-energy use is increasing over time; from the global perspective from $1 \%$ in 1970 to $3 \%$ in 1995. Similarly, the share of $\mathrm{CO}_{2}$ from feedstocks in the total emissions from non-energy use has increased from about 55\% in 1970 to 80\% in 1995 globally [12,13]. Depending on the country, the share of non-energy use of fossil fuels in total energy balance varies, depending on the importance of refineries and basic chemical industries [11,14].

A number of hydrocarbons are used for non-energy purposes, for instance petrochemical feedstocks, lubricants, solvents, and bitumen. The carbon in the fuel is either oxidized to $\mathrm{CO}_{2}$, or it is stored in the product. It is possible, that the carbon is stored in the product for decades, or even centuries [15].

\section{Reporting of Non-Energy Use of Fuels Under IPCC 2006 Guidelines}

From the 2015 submission onward, it is required to use the Reference Approach in line with IPCC 2006 Guidelines [10]. The main difference between the new reference approach and the old one, used to date [8], is that instead of the concept of "long-term stored carbon" (stored carbon), used for some non-energy fuels, now a new, broader concept-"excluded carbon"-is used, which includes not only the stored carbon, but also carbon used and emitted as $\mathrm{CO}_{2}$ in other sectors, not only in the Energy Sector 1.A (most often in the sector 2 IPPU). The reference approach, as a top-down independent estimate of $\mathrm{CO}_{2}$ emissions from fuel combustion, serves basically as verification of the sectoral approach, i.e., what is used in the inventory for estimation of emissions from the energy sector; therefore it is important that $\mathrm{CO}_{2}$ accounted for in other sectors is not part of the comparison of the two approaches. This means that the "excluded carbon" is deducted from the total carbon, calculated on the basis of the apparent domestic consumption (apparent consumption). This is mainly necessary for carbon contained in fossil fuels used as:

1. Raw materials for further treatment in the industry (feedstocks),

2. Reductants,

3. Non-energy products.

An overview of materials containing "excluded carbon" is shown in Table 1.

Table 1. Products used as feedstocks, reductants, and for non-energy products [10].

\begin{tabular}{cc}
\hline Feedstocks & Naphtha \\
\hline & LPG (propane-butane) \\
& Oils used as feedstocks \\
& Refinery gas \\
& Natural gas \\
& Ethane \\
\hline Reductants & Metallurgical coke and petroleum coke \\
& Coal and coal tar/pitch \\
& Natural gas \\
\hline Non-energy products & Bitumen \\
& Lubricants \\
\hline
\end{tabular}

For fuels that are used in sectors other than the Energy Sector (i.e., non-energy fuels: For example coke or naphtha), it is necessary to know the quantity of the particular material that is used outside the Energy Sector (e.g., as feedstock or reductant). The IPPU sector consists of a number of subcategories, where the non-energy use of fuels can occur. Table 2 lists subcategories of the IPPU sector. The last column indicates, whether the non-energy use of fuels can occur in the relevant category. 
Table 2. List of subcategories of the industrial processes and other product use (IPPU) sector [10].

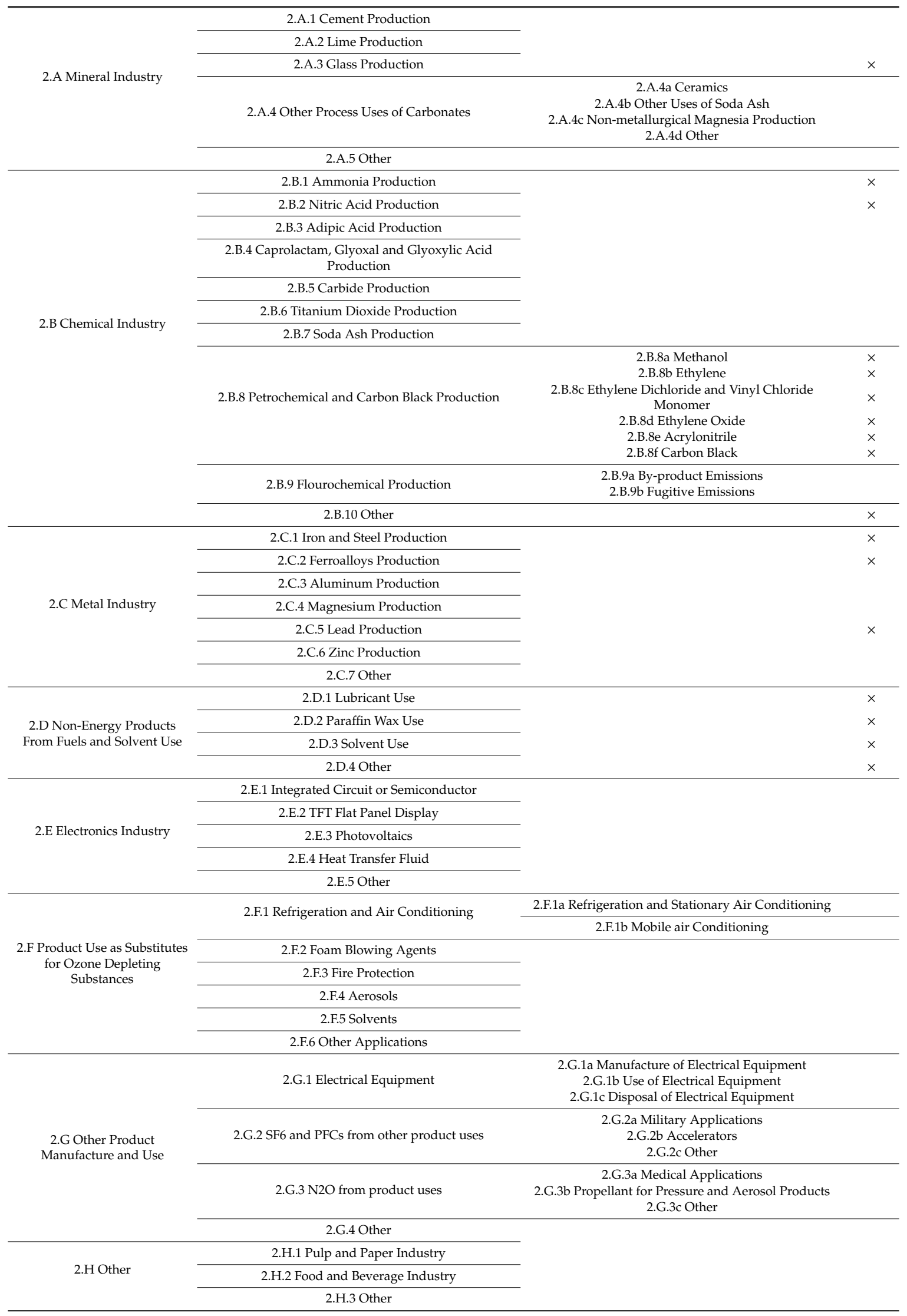




\section{Feedstocks and Non-Energy Use of Fuels}

The IPCC 2006 Guidelines [10] clearly sets the borderlines between the Energy and Industrial Processes and Product Use sectors. Compared to the previous methodology version [8], emissions from non-energy use of fuels are reported mainly in the IPPU sector. To prevent double counting or omission of resources, it is necessary to carefully carry out a comprehensive check of $\mathrm{CO}_{2}$ emissions in sectors Energy-combustion and IPPU, for those kinds of fuels that are used for both energy and non-energy purposes.

Non-energy fuels are divided into three categories:

1. Raw materials for the chemical industry (feedstocks). These fossil fuels are used in particular in the production of organic compounds and to a lesser extent in the production of inorganic chemicals (e.g., ammonia) and their derivatives. For organic substances, part of the carbon contained in the feedstock normally remains largely stored in these products. Typical examples of raw materials are feedstocks for the petrochemical industry (naphtha), natural gas, or various types of oils (e.g., the production of hydrogen for the subsequent production of ammonia by partial oxidation).

2. Reductants. Carbon is used as a reductant in metallurgy and inorganic technologies. Unlike the previous case, here, when using fossil fuel as reductant, only a very small amount of carbon remains fixed in the products for a longer time and larger part of the carbon is oxidized during the reduction process. Metallurgical coke is a typical reductant.

3. Non-energy products. Non-energy products are materials derived from fuels in refineries or coke plants which, unlike the previous two cases, are used directly for their conventional physical properties, specifically as lubricants (lubricating oils and petrolatum), diluents and solvents, bitumen (for covering roads and roofs), and paraffin. Emissions of $\mathrm{CO}_{2}$ and other GHG occur only to a limited extent in the IPPU category (e.g., during the oxidation of lubricants and paraffin). Substantial emissions occur during their recovery and during their disposal by incineration (in the Energy and in Waste Sectors) [16].

The IPCC 2006 Guidelines [10] provide a general framework methodology for the Reference Approach/Sectoral Approach comparison using so called excluded carbon. However, this general framework is appropriate only for solving simple problems associated with non-energy use of fuels. There are many other complex types of productions or methods of non-energy fuels use that require a specific approach to address them. This paper focused on ways how to address non-energy use of fuels and it lists the links between non-energy use and IPPU categories. An example of the three neighboring countries presents the methods of solution for various complex productions as well as for the different types of available data in the country.

\section{Reporting of Non-Energy Use of Fuels in the Inventory of the Czech Republic}

Emissions from feedstocks in the chemical industry are reported in subsector 2.B, Chemical Industry, from reductants primarily in subsector 2.C, Metal Industry and from non-energy products, used mainly for purposes other than combustion (e.g., lubricating oils) in subsector 2.D, Non-energy Products from Fuels and Solvent Use [16].

Some types of liquid fuels are designed mainly for non-energy use. This is primarily naphtha; liquified petroleum gas (LPG) might also be the case [16].

Another important type of liquid fuel consumed for non-energy purposes of fuels is a group designated as other oils. Their most significant share is other petroleum products, which find application in the production of hydrogen by partial oxidation with steam for subsequent production of ammonia. Another part of it is also included under solvent use [16].

White spirit and paraffin wax are usually less important categories and they are indeed used only for non-energy purposes in 2.D [16]. 
Liquid fuels used especially for non-energy purposes also include bitumen and lubricants. While there are practically no emissions of $\mathrm{CO}_{2}$ in the use of bitumen (stored carbon), in the use of lubricants part is oxidized to $\mathrm{CO}_{2}$ (reported in 2.D) [16]. The respective amount of the fuel used in non-energetical way is used for the emission estimates as activity data. Either default, or country specific emission factors are applied for the emission calculation.

Solid fuels for non-energy purposes are mainly used as reductants. These include coke (coke oven coke) in the production of iron and steel (2.C). Further, coal tar is used as well [16]. $\mathrm{CO}_{2}$ emissions from the iron and steel in the Czech inventory are calculated using the carbon balance of the process following the approach presented in the IPCC 2006 Guidelines [10]. In many countries, natural gas (NG) is also used as a feedstock. It has not been used in the Czech Republic until recently and since 2008 Czech Statistical Office has indicated that approximately $1 \%$ of annual consumption of natural gas in the Czech Republic is used for non-energy purposes in the chemical industry. This non-energy use is reported under 2.B.10 (for the use of non-selective catalytic reduction) [16]. The $\mathrm{CO}_{2}$ emissions are estimated using a country specific emission factor for $\mathrm{CO}_{2}$ from the natural gas combustion and using the amount of the natural gas used in the chemical industry.

Fuels for non-energy use are not accounted for in the sectoral approach in category 1.A. In the reference approach, non-energy use is deducted from the apparent consumption as excluded carbon [16].

Table 3 provides allocation of the non-energy use of fuels in the IPPU sector in the Czech Republic.

Table 3. The allocation of non-energy use of fuels in the IPPU sector in the Czech Republic.

\begin{tabular}{cc}
\hline Fuel & Used and Reported in Categories \\
\hline Gas/diesel oil & $\begin{array}{c}\text { 2.B.1 Ammonia Production } \\
\text { 2.B.8 Petrochemicals }\end{array}$ \\
\hline Liquefied petroleum gases & 2.B.8 Petrochemicals \\
\hline Naphtha & 2.B.8 Petrochemicals \\
\hline Lubricants & 2.D.1 Lubricants Use \\
\hline Other Oil & 2.B.1 Ammonia Production \\
\hline Other bituminous coal & 2.C.1 Iron and Steel Production \\
\hline Coke & 2.C.1 Iron and Steel Production \\
\hline Natural Gas & 2.B.10 Other \\
\hline
\end{tabular}

\section{Reporting of Non-Energy Use of Fuels in the Inventory of the Slovak Republic}

In Slovakia, several types of fuels are used as feedstocks and for non-energy use. When categorization of non-energy fuels as described above Table 1 is used then all of these categories apply in Slovakia [17]:

1. Feedstocks: Naphtha, refinery gas, and natural gas;

2. Reductants: Coking coal, other bituminous coal, coke, and petroleum coke;

3. Non-energy products: Lubricants, paraffin wax and white spirit, and bitumen.

Reporting of these fuels is summarized in Table 4.

Non-energy products as lubricants, paraffin wax, and white spirit evolve a part of the stored carbon in the form of $\mathrm{CO}_{2}$ and they are reported accordingly (please see Table 4). It is assumed that $20 \%$ of stored carbon evolves as $\mathrm{CO}_{2}$ emission [10]. On the other hand, the use of bitumen does not create the emissions of $\mathrm{CO}_{2}$; all carbon in bitumen is stored permanently.

Natural gas is used for several purposes in Slovakia. The main part of non-energy use of natural gas serves as a feedstock for ammonia production. In this case the natural gas serves not only as a feedstock but also as fuel for heating. The whole amount of the natural gas used is excluded from the reference approach and reported in IPPU (2.B.1). Another significant non-energy use of the natural gas is a hydrogen production. 
It is produced by steam reforming of natural gas, which is the same process as in ammonia production. Therefore the same approach has been followed and all $\mathrm{CO}_{2}$ emissions are reported in IPPU (2.B.10) [17].

Table 4. The allocation of non-energy use of fuels in the IPPU sector in Slovakia.

\begin{tabular}{cc}
\hline Fuel & Used and Reported in Categories \\
\hline Natural gas & 2.B.1 Ammonia Production \\
& 2.B.8 Petrochemicals \\
2.B.10 Hydrogen Production & 2.C.1 Iron and Steel Production \\
\hline Naphtha & 2.B.8 Petrochemicals \\
\hline Lubricants & 2.D.1 Lubricants Use \\
\hline Paraffin wax and white spirit & 2.D.2. Paraffin Wax Use \\
\hline Bitumen & 2.D.3 Solvents Use \\
\hline Refinery feedstocks & 2.B.8 Petrochemicals \\
\hline Petroleum coke & 2.C.3 Aluminum Production \\
\hline Coking coal & 2.B.5 Carbide Production \\
& 2.C.1 Iron and Steel Production \\
2.C.2 Ferroalloys Production \\
\hline Other bituminous coal & 2.B.5 Carbide Production \\
& 2.C.1 Iron and Steel Production \\
2.C.2 Ferroalloys Production \\
\hline Coke & 2.C.1 Iron and Steel Production \\
\hline
\end{tabular}

Petroleum coke is used for production of aluminum. Petroleum coke is mixed with tar and filled in the casting forms in order to produce pre-baked anodes. The respective amounts of petroleum coke used are reported in statistics for reference approach; therefore they are subtracted from the reference approach and reported in IPPU sector (2.C.3). The tar used is not presented in statistics; therefore it is not deducted from reference approach while it is still reported in IPPU sector [17].

Coking coal and other bituminous coal are used for the production of calcium carbide, ferroalloys, and iron and steel. The reporting of non-energy use of these fuels is quite simple for calcium carbide and ferroalloys production. The fuels used as material feedstock to the process are excluded from the reference approach and they are reported in the respective category of IPPU. Iron and steel production is a complex process. Use of the coking coal, other bituminous coal, and coke results in the carbon stored in the products, $\mathrm{CO}_{2}$ emissions, and the production of other fuels (blast furnace gas and coking gas) that are used for energy purposes in the plant [17]. The calculation of the carbon that should be excluded from the reference approach is based on the simplified scheme depicted in Figure 1.

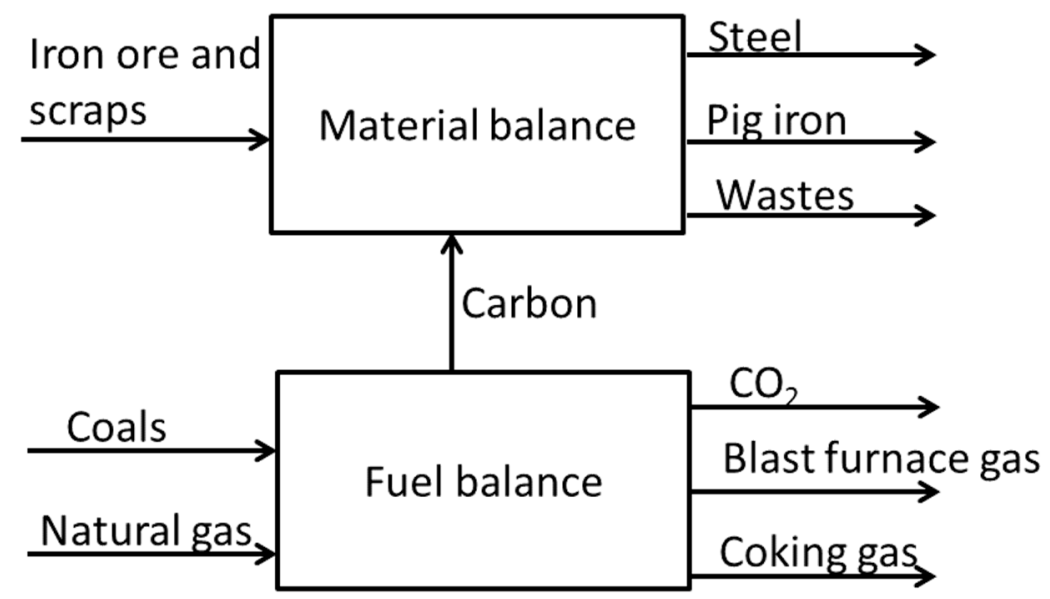

Figure 1. Scheme of the calculation of carbon stored in the products from iron and steel production. 
The "Carbon" flow in Figure 1 represents the amount of carbon that is stored in products (main products and by-products). This amount can be obtained from the difference between carbon contained in all products and in raw materials (iron ore and scraps). It should be mentioned that "Pig iron" flow represents the amount of pig iron that is not processed into steel. Based on the scheme in Figure 1, the carbon that is excluded from the reference approach is the sum of the carbon that is stored in products and carbon contained in $\mathrm{CO}_{2}$ emissions. These emissions are reported in IPPU (2.C.1) [17].

Another complex solution occurs at ethylene production. The simplified scheme is shown in Figure 2.

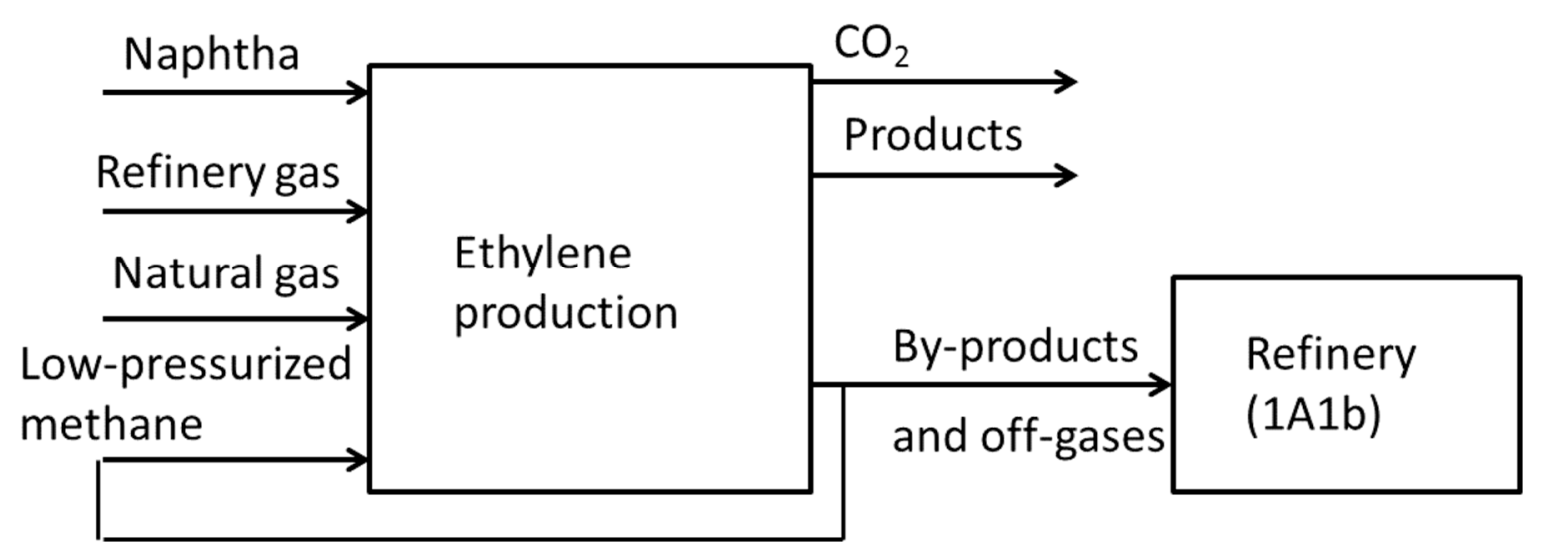

Figure 2. Scheme of the ethylene production.

Naphtha, refinery gas, low-pressurized methane, and natural gas are used as feedstocks. During the reaction in the ethylene unit a refinery gas with high content of methane is formed. This methane is separated from the refinery gas and creates an inner loop in the process. Therefore the low-pressurized methane cannot be excluded from the reference approach. The rest of refinery gas (after separation of methane) is going into refinery and it represents an input stream for emission estimates in the Energy Sector (1.A.1.b category). On the other hand, another stream of refinery gas is outgoing from refinery and it represents the input stream in the ethylene unit Figure 2. The naphtha stream also originates in the refinery. The total amount of carbon excluded from the reference approach is the difference between the carbon contained in input flows (naphtha, excess refinery gas, and natural gas) and the carbon in off-gases going to the refinery. Part of it is stored in products (ethylene and propylene) and the rest is evolved as $\mathrm{CO}_{2}$ emissions that are reported under IPPU (2.B.8). This approach (including the inner loop into the calculation of emissions) is chosen because of comparability with the EU ETS report where the emission estimates are calculated on the basis of fuel combustion [17].

It should be mentioned that $\mathrm{CO}_{2}$ emissions in respective IPPU categories are calculated using carbon balance that is in agreement with IPCC 2006 Guidelines [10]. The overall approach is to calculate the amount of carbon originating from inputs to the process; and then subtracting of the stored carbon amounts. The rest of carbon evolves as $\mathrm{CO}_{2}$ emissions.

\section{Reporting of Non-Energy Use of Fuels in the Inventory of Hungary}

Similar to other countries, all three categories of non-energy use, i.e., as feedstocks (especially naphtha, LPG, gasoil, natural gas, and tars), as reductants (especially coke oven coke, coke oven gas, and natural gas), and as non-energy products (especially lubricants, paraffin wax and white spirit, and bitumen) occur in Hungary [18]. Their allocation in the inventory is summarized in Table 5.

Although the International Energy Agency (IEA) Annual Questionnaires that serve as a basis of the inventory preparation clearly separate energy and non-energy use of fuels, the data cannot be used without further modification by the inventory compilers. In the following two cases the original IEA energy balance is modified with additional data obtained from the firms concerned. 
Table 5. The allocation of non-energy use of fuels in the IPPU sector in Hungary.

\begin{tabular}{cc}
\hline Fuel & Used and Reported in Categories \\
Natural gas & 2.B.1 Ammonia Production, Hydrogen Production, Nitric Acid \\
& Waste Gas Scrubbing \\
& 2.B.8 Petrochemicals \\
& 2.C.1 Iron and Steel Production \\
\hline Naphtha & 2.B.8 Petrochemicals \\
\hline Lubricants & 2.D.1 Lubricants Use \\
& 1.A.3.b Road Transport \\
\hline Paraffin wax & 2.D.2. Paraffin Wax Use \\
\hline Gas-Diesel oil & 2.B.8 Petrochemicals \\
\hline White spirit & 2.B.8 Petrochemicals \\
\hline LPG & 2.B.8 Petrochemicals \\
\hline Other oil products & 2.B.8 Petrochemicals \\
\hline Coke & 2.C.1 Iron and Steel Production \\
\hline Coke Oven Gas & 2.C.1 Iron and Steel Production \\
\hline Blast Furnace Gas & 2.C.1 Iron and Steel Production \\
\hline
\end{tabular}

The allocation of natural gas is different in the inventory than according to the IEA for the reasons described below. In the inventory, a balance (energy use + non-energy use reported in the IEA energy balance minus all natural gas accounted for in the IPPU sector) for all natural gas used in the chemical industry is calculated. The remaining part of the natural gas that is not accounted for in the IPPU sector is allocated in the category 1.A.2.C of the Energy Sector [18].

In the case of other (oil) products, and also for naphtha LPG, the IEA Annual Questionnaires allocation is not consistent for the whole time-series; part of the total consumption reported as energy use and part classified as non-energy use in the energy statistics are not consistent in time-series. However, the IPCC 2006 Guidelines advice to allocate all such emissions to the IPPU sector irrespective of whether they arising from energy or non-energy use of fuel [18].

\subsection{Feedstocks in Hungarian Inventory}

Ammonia production: Currently, there are only two ammonia plants in Hungary. In the inventory, the reporting scheme of the largest (EU ETS) plant is basically followed, which is in line with the IPCC 2006 Guidelines [10]. It means that all natural gas used for ammonia production (either classified previously as technological gas or as fuel) is allocated in the IPPU sector [18].

$\mathrm{H}_{2}$ production: Natural gas used for $\mathrm{H}_{2}$ production outside the ammonia plants is also allocated in the category 2.B.1, because one of the ammonia production plants uses hydrogen (that is produced from natural gas by another plant) for ammonia production. On the other hand, the hydrogen plant of the Hungarian oil refinery is not allocated in the 2.B.1 category but in the Energy Sector. Similarly, petroleum coke use for catalyst regeneration and the resulting $\mathrm{CO}_{2}$ emission are accounted for in the Energy Sector (1.A.1.b), and the corresponding amount of petroleum coke remains in the reference approach [18].

Olefin production: Yearly (500-600) kt of ethylene and propylene is produced in the largest petrochemical plant of Hungary, which serve as feedstock for basic plastics (polyethylene, polypropylene) production. As a recent development, butadiene is recovered as a by-product of the ethylene production. For olefin production, mostly naphtha, LPG, and gasoil are used. In the inventory, the EU ETS report of the plant is directly used. The EU ETS monitoring regulation allows for facilities for production of bulk organic chemicals to choose between the mass balance methodology that is based on the amount and the carbon content of material entering or leaving the facility and the 
standard methodology that is based on fuel use. This plant follows the latter approach; therefore the EU ETS reports do not provide information about carbon stored in the products. On the other hand, the time-series of non-energy use of oil products (as raw material in petrochemical production) is present in energy statistics provided by IEA, even though in a not fully consistent manner as described above. These data have been taken into account and all of the carbon from these sources was excluded from the Energy Sector and reported in IPPU [18].

Carbon black production: The plant uses mainly tar ("quench oil") coming from the refinery or as a by-product from the olefin plant with some imported amount. In addition, natural gas is used in the production process. In the mass balance approach applied by the plant, the carbon content of a small amount of imported carbon black, some toluene, waste oil, and potassium carbonate are taken into account. In the inventory, ETS data are directly used [18].

Vinyl chloride monomer (VCM) and toluene diisocyanate (TDI) production: VCM is the key material for PVC production. Ethylene dichloride (EDC) is the intermediate product during VCM production, where the EDC cracking furnace uses natural gas. TDI is an aromatic diisocyanate and a key polyurethane raw material. During TDI production natural gas is used for combustion of by-products and the generated heat is used for other chemical processes in this plant [18].

Based on the information from the energy statistics provider, all naphtha, and most LPG, gasoil, and all relevant other oil products allocated to the chemical and petrochemical categories in the energy statistics (either for energy or for non-energy uses) are used up in the above described petrochemical production processes, therefore the emissions from the EU ETS reports of the three relevant large plants are included without any modification in the category 2.B.8, Petrochemical and Carbon Black Production, so $100 \%$ share of ETS emissions is achieved in this category. Consequently, the above oil products are removed from the reference approach irrespective whether they are allocated to the energy or non-energy consumption in the energy statistics [18].

\subsection{Reductants in Hungarian Inventory}

Iron and steel production: In the used approach, basically all emissions from the blast furnace and the sinter plant are allocated to the IPPU sector. It means, for example, that all coke-related emissions are accounted for in the category 2.C.1 (IPPU, Iron and Steel Production). Thus all coke allocated in the energy statistics to iron and steel production or transformation in blast furnaces categories is removed from the reference approach. By doing so, recovered blast furnace gas combusted for electricity purposes needs to be taken into account. The respective amount of blast furnace gas and the corresponding carbon are subtracted from 2.C.1 and allocated to the 1.A.1.a category of the Energy Sector [18].

\section{Discussion}

Methodology published in the IPCC 2006 Guidelines gives robust background for non-energy use of fuels reporting. In majority of the cases, this methodology is fully applicable. Activity data necessary for calculation can be found in the national statistics, EU ETS reports or in the international databases (such as IEA). Data consistency shall be ensured by using different sources or databases for inputs. The most common is that different statistics does not use the same methodology for energy and non-energy uses of fuels and the consistency of time-series can be questionable.

The conservative approach shall be applied when statistical data are used for reporting, the splitting of energy and non-energy uses of fuels is usually not consistent with the IPCC methodology. The individual approach is necessary. A good example of the calculation approach is using the sum of energy and non-energy statistical data following the subtraction of fuels used in the IPPU sector. The result is the "energy use" reported in the inventory. If some productions/products are reported energy and non-energy uses of fuels separately in the statistics, followed the IPCC 2006 Guidelines it is necessary to report this total in the IPPU sector. It means that this total represents only non-energy use of fuels (NEU) part of fuels. The typical example is ammonia production. 
Hydrogen production requires individual approach. Two different methodological ways exist in emission reporting in the hydrogen production in refinery. If detail flows of fuels and products inside refinery are known and the hydrogen production can be identified and separated, then it is possible to report these emissions in the category 2.B.10 in the IPPU sector and at the same time removing natural gas consumption from the reference approach. This approach was used in the Slovak and Czech inventory. Inventory reported by Hungary uses a different approach. Separation of hydrogen production in a refinery is not possible based on available data, therefore refinery is balanced in the energy sector in ones and the fuel consumption is not NEU.

Organic products balanced in refineries is a complex issue. The EU ETS methodology allows two approaches: The mass balance methodology, which is based on the volume and carbon content of material entering or leaving the facility and the standard methodology based on fuel use. If mass balance is used, the NEU can be easily reported, if the EU ETS facility uses the second approach, the NEU cannot by reported separately. In this case, additional data for mass balance of the production stream in refinery are necessary. Afterwards, the NEU can be balanced similarly as in the case of Slovakia. Complementary, also other data sources can be used, such example is the IEA database. International data can be used in the inventory without additional consideration, which is an example of Hungary. Hungarian experts found the IEA data reliable for using in the inventory, time series consistency shall be approved carefully, mostly for the review process. Including international data into national inventory improved Hungarian estimation in the NEU reporting. Ignoring NEU and reporting emissions exclusively in the energy sector overestimate emissions (if the carbon in products is not excluded) or implied emission factor (IEF) calculated by this approach will be out of range (when part of carbon will be stored in products).

\section{Conclusions}

Energy and IPPU sectors account to the majority of the greenhouse gas inventories for up to $90 \%$ of the total greenhouse gas emissions arising in the region of specific country. In order to keep the reporting transparent and accurate a clear distinction between technological and combustion processes has to be considered.

In the special case of non-energy use of fuels, the inventory compilers have to pay special attention to neither double-count, nor omit relevant $\mathrm{CO}_{2}$ emissions. In order to do so, the inventory compilers have to have access to the relevant data about industrial production. Understanding of the production processes is crucial as well.

IPCC 2006 Guidelines [10] give a general guidance on how to approach reporting of such an emission. As it can be seen from the Sections 3-5, each country has its specific use of fuels for the technological purposes and specific methods of obtaining the relevant data about the carbon excluded from RA based on the available activity data. However, the general approach remains comparable.

The authors of the paper believe that presented approaches of reporting of non-energy use of fuels in the greenhouse gas inventory can also serve as guidance for other countries.

Author Contributions: Conceptualization, E.K. and J.S.; methodology, E.K., V.N., J.S. and V.D.; investigation, V.D., J.S., K.T., G.K., V.N.; resources, V.D., J.S., K.T., G.K., V.N.; data curation, V.D., J.S., K.T., G.K., V.N.; writing—original draft preparation, E.K.; writing-review and editing, V.D., J.S., K.T., G.K., V.N.

Funding: This research received no external funding.

Conflicts of Interest: The authors declare no conflict of interest.

\section{References}

1. Krtková, E. Inventory of the greenhouse gas emissions in the Czech Republic (in Czech). In In Meteorological Bulletin; Czech Hydrometeorological Institute: Prague, Czech Republic, 2016; Volume 69, ISSN 0036-1173. 
2. Sebos, I.; Progiou, A.; Kallinikos, L.; Eleni, P.; Katsavou, I.; Mangouta, K.; Ziomas, I. Energy, Transportation and Global Warming, Mitigation and adaptation policies related to climate change in Greece. Green Energy Technol. 2016, 2, 35-49.

3. Sebos, I.; Papathanasiou, S.; Ziomas, I. Methodological Framework for the Assessment of the Progress of European Union Member States towards reaching their Commitments under the Kyoto Protocol. Eng. Fresenius Environ. Bull. 2003, 22, 2128-2138.

4. Bergamaschi, P.; Danila, A.; Weiss, R.F.; Ciais, P.; Thompson, R.L.; Brunner, D.; Levin, I.; Meijer, Y.; Chevallier, F.; Janssens-Maenhout, G.; et al. Atmospheric Monitoring and Inverse Modelling for Verification of Greenhouse Gas Inventories; Publications Office of the European Union: Luxembourg, Luxembourg, 2018.

5. UNFCCC. Decision 1/CMP.8 Amendment to the Kyoto Protocol pursuant to its Article 3, paragraph 9 (the Doha Amendment). Available online: https:/unfccc.int/process-and-meetings/conferences/past-conferences/ doha-climate-change-conference-november-2012/cmp-8/cmp-8-decisions (accessed on 10 June 2019).

6. EU. Regulation (EU) No 525/2013 of the European Parliament and of the Council of 21 May 2013 on a mechanism for monitoring and reporting greenhouse gas emissions and for reporting other information at national and Union level relevant to climate change and repealing Decision No 280/2004/EC. Available online: http://eur-lex.europa.eu/LexUriServ/LexUriServ.do?uri=OJ:L:2013:165:0013:0040:en:PDF (accessed on 19 June 2019).

7. EU. Decision No. 280/2004/EC of the European Parliament and of the Council concerning a mechanism for monitoring Community greenhouse gas emissions and for implementing the Kyoto Protocol. Available online: https://www.ecolex.org/details/legislation/decision-no-2802004ec-of-the-european-parliamentand-of-the-council-concerning-a-mechanism-for-monitoring-community-greenhouse-gas-emissions-andfor-implementing-the-kyoto-protocol-lex-faoc041216/ (accessed on 9 May 2019).

8. IPCC. Revised 1996 IPCC Guidelines for National Greenhouse Gas Inventories. Available online: www.ipccnggip.iges.or.jp/public/ (accessed on 2 May 2019).

9. IPCC. Good Practise Guidance and Uncertainty Management in National Greenhouse Gas Inventories, IPCC 2000. Available online: www.ipcc-nggip.iges.or.jp/public/ (accessed on 19 June 2019).

10. IPCC. 2006 IPCC Guidelines for National Greenhouse Gas Inventories, Vol. 1-5. Available online: www.ipccnggip.iges.or.jp/public/ (accessed on 19 June 2019).

11. Aresta, M.; Dibenedetto, A.; Angelini, A. From $\mathrm{CO}_{2}$ to Chemicals, Materials, and Fuels: The Role of Catalysis. Encycl. Inorg. Bioinorg. Chem. 2014, 1-18. [CrossRef]

12. Patel, M.; Neelis, M.; Gielen, D.; Olivier, J.; Simmons, T.; Theunis, J. Carbon dioxide emissions from non-energy use of fossil fuels: Summary of key issues and conclusions from the country analyses. Resour. Conserv. Recycl. 2005, 195-209. [CrossRef]

13. Olivier, J.G.; Peters, J.A. $\mathrm{CO}_{2}$ from non-energy use of fuels: A global regional and national perspective based on the IPCC Tier 1 approach. Resour. Conserv. Recycl. 2005, 210-225. [CrossRef]

14. Neelis, M.L.; Patel, M.; Gielen, D.J.; Blok, K. Modelling $\mathrm{CO}_{2}$ emissions from non-energy use with the non-energy use emissions accounting tables (NEAT) model. Resour. Conserv. Recycl. 2005, 226-250. [CrossRef]

15. IEA. $\mathrm{CO}_{2}$ Emissions from Fuel Combustion Highlights; International Energy Agency: Paris, French, 2017.

16. Czech Hydrometeorological Institute (ČHMÚ). National inventory report (online). Available online: http://portal.chmi.cz/files/portal/docs/uoco/oez/nis/nis_do_cz.html (accessed on 19 June 2019).

17. Slovak Hydrometeorological Institute (SHMÚ). National inventory report (online). Available online: http://ghg-inventory.shmu.sk/documents.php?lang=2 (accessed on 19 June 2019).

18. Hungarian Meteorological Service (OMSZ). National inventory report (online). Available online: https:/unfccc.int/process/transparency-and-reporting/reporting-and-review-under-the-convention/ greenhouse-gas-inventories-annex-i-parties/submissions/national-inventory-submissions-2017 (accessed on 19 June 2019).

(C) 2019 by the authors. Licensee MDPI, Basel, Switzerland. This article is an open access article distributed under the terms and conditions of the Creative Commons Attribution (CC BY) license (http://creativecommons.org/licenses/by/4.0/). 